
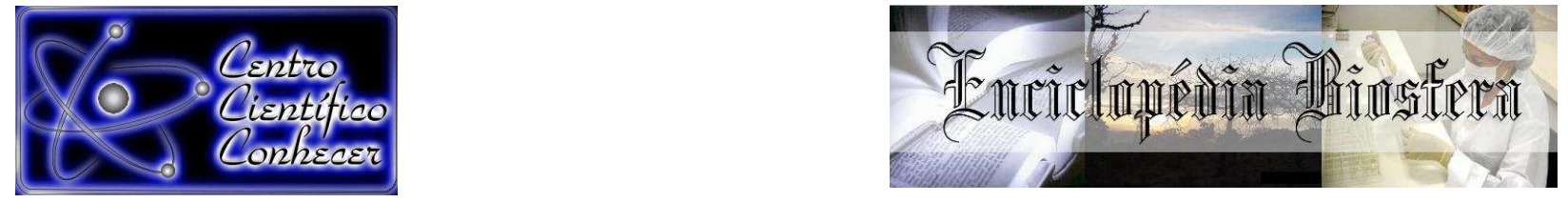

\title{
ANÁLISE DE SUSCETIBILIDADE EROSIVA NO MUNICÍPIO DE BARCARENA - PA
}

Felipe Antonio Melo da Costa Filho'; Afonso Segtowich Sarmanho Beltrão; Gundisalvo Piratoba Morales; ; Hebe Morganne Campos Ribeiro ${ }^{4}$; Manuel Alejandro Piratoba Vera ${ }^{5}$

1 Graduando, em Engenharia Ambiental - Uepa -CCNT (famcf02@hotmail.com)

${ }^{2}$ Graduando, em Engenharia Ambiental - Uepa -CCNT

${ }^{3}$ Professor Doutor da Universidade do Estado do Pará - UEPA

4 Professor Doutor da Universidade do Estado do Pará - UEPA

${ }^{5}$ Graduando, em Engenharia Ambiental - IESAM

Recebido em: 08/09/2015 - Aprovado em: 14/11/2015 - Publicado em: 01/12/2015

DOI: http://dx.doi.org/10.18677/Enciclopedia_Biosfera_2015_075

\begin{abstract}
RESUMO
Erosão é a forma mais agressiva de degradação da paisagem, sendo acelerada de pelas atividades antrópicas. Assim, este trabalho teve como objetivo analisar a suscetibilidade à erosão no município de Barcarena, no estado do Pará, através da elaboração de carta de suscetibilidade erosiva, com o intuito de promover uma melhor gestão dos recursos naturais. Para obtenção do mapa de suscetibilidade erosiva, foi realizada a análise multicritério, além desta, foi aplicado também o método de álgebra de mapas. O município de Barcarena possui uma área de aproximadamente 1.305,57 km², desta área 42,12\% $\left(549,88 \mathrm{~km}^{2}\right)$ enquadraram-se como área de suscetibilidade erosiva Média, 28,06\% $\left(366,43 \mathrm{~km}^{2}\right) \mathrm{com}$ área de suscetibilidade Muito Alta, 25,88\% $\left(337,92 \mathrm{~km}^{2}\right)$ com susceptibilidade Alta, 3,43\% $\left(44,73 \mathrm{~km}^{2}\right)$ como área de susceptibilidade Baixa e apenas $0,51 \%\left(6,61 \mathrm{~km}^{2}\right) \mathrm{com}$ suscetibilidade erosiva Muito Baixa. Através dos resultados obtidos com a pesquisa foi possível observar que o município de Barcarena apresenta uma fragilidade ambiental considerável, onde a maior parte de sua área é passiva a processos erosivos de Média intensidade a Muito Alta, logo é importante que os gestores e a população, tenham consciência do cenário ambiental em que o seu município enquadra-se atualmente. Deste modo, estudos com objetivos e metodologias semelhantes aos usados nesta pesquisa podem ser aplicados em áreas similares da região amazônica, para gerar subsídios que redundem no gerenciamento ambiental de áreas que estão cada vez mais expostas as atividades antrópicas.
\end{abstract}

PALAVRAS-CHAVE: Barcarena-Pa, erosão, suscetibilidade.

\section{ANALYSE OF SUSCEPTIBILITY TO EROSION IN BARCARENA - PA}

\section{ABSTRACT}

Erosion is probably the most severe form of landscape degradation around the globe, and human activities have accelerated these processes. Thus, this study aimed to analyze the susceptibility to erosion in Barcarena, state of Pará, by drafting letter of ENCICLOPÉDIA BIOSFERA, Centro Científico Conhecer - Goiânia, v.11 n.22; p.107 2015 
erosive susceptibility, in order to promote better management of natural resources. To obtain the erosive susceptibility map, the multi-criterial analysis was performed in addition to this, it was also applied algebra method maps. The Barcarena has an area corresponding to approximately 1305.57 square kilometers, of all area, $42.12 \%$ $\left(549.88 \mathrm{~km}^{2}\right)$ framed up the study area as erosive susceptibility Average, $28.06 \%$ $\left(366.43 \mathrm{~km}^{2}\right)$ with susceptibility Very High, $25.88 \%\left(337.92 \mathrm{~km}^{2}\right)$ to High, $3.43 \%$ $\left(44,73 \mathrm{~km}^{2}\right)$ to Low and just $0.51 \%\left(6.61 \mathrm{~km}^{2}\right)$ with erosive susceptibility Very Low.Through the results of the survey it was observed that the municipality of Barcarena presents a considerable environmental fragility, where most of its area is the passive erosion between Medium intensity and Very High, so it is important that managers and the public, are aware of the environmental scenario in which your municipality falls today. Therefore, studies with goals and methodologies similar to this research should be applied, shaped and funded, considering their importance for environmental management areas that are increasingly exposed human activities development.

KEYWORDS: Barcarena-Pa, Erosion, Susceptibility.

\section{INTRODUÇÃO}

Dentre as principais alterações no uso do solo, a erosão é, provavelmente, a forma mais grave de degradação da paisagem ao redor do globo, e as atividades antrópicas têm acelerado esses processos. A degradação ambiental causada pelos processos erosivos tem se tornado mais evidente e torna-se necessário, cada vez mais, não apenas reverter esse processo, mas também prever danos futuros com base no planejamento e gestão desses recursos (XAVIER et al. 2010).

Segundo BONNA (2011), a erosão é um processo natural que envolve a remoção de partículas, transporte e deposição lenta ou acelerada dos materiais, sejam eles constituídos por materiais rochosos, solos ou depósitos superficiais inconsolidados. Estudos de MAGRI (2013) mostram a ocorrência de graves processos erosivos no Brasil, destacando as regiões do Noroeste do Paraná, interior de Minas Gerais, Rio de Janeiro, São Paulo e Sul do Mato Grosso, como as mais afetadas. Efeitos negativos dos processos erosivos acarretam na improdutividade das terras, o assoreamento de cursos d'água, gerando elevadas perdas econômicas à sociedade. MAGRI (2013) ainda menciona grandes processos erosivos em regiões ocupadas recentemente nos Estados de Rondônia, Mato Grosso, Pará e enfatiza itens como a degradação do solo e da paisagem causada principalmente pela erosão nas cabeceiras dos rios Xingu e Araguaia.

MINELLA et al. (2007), mostraram o uso inadequado do solo como um dos fatores antrópicos preponderantes que aumentam a suscetibilidade erosiva regional. O uso inadequado do solo, diferentes à sua aptidão, tem contribuído gradativamente para a sua degradação nos processos erosivos presentes em áreas com maior declividade, associadas com solos de texturas mais arenosas e ausência de práticas de conservação adequadas (COSTA et al. 2010).

Em geral a erosão é uma das principais causas da degradação dos solos, que podem ser agravados pelas suas características físicas impróprias à ocupação antrópica, em especial as características geológicos, geomorfológicos, pedológicos e topográficos, que podem tornar mais agressivos processos erosivos (SIMÕ̃ES \& OLIVEIRA, 2014).

Uma maneira de avaliar a tendência à processos erosivos em um determinado ambiente é através das cartas de suscetibilidade erosiva. A 
susceptibilidade erosiva pode ser avaliada com base nos fatores naturais e antrópicos da área, como a topografia, a ausência de vegetação nativa, a pedologia, hidrografia, clima, entre outros, por exemplo LOLLO \& SENA (2012), elaboraram cartas de susceptibilidade erosiva com base no tipo do solo, tipo de substrato ou rocha, geomorfologia, declividade e o uso e ocupação do solo. As cartas de suscetibilidade são geradas utilizando um software de Sistemas de Informação Geográfica SIG, onde os mapas analíticos e temáticos dos atributos naturais e antrópicos da área estudada são sobrepostos e combinados através de operações matemáticas com base em critérios de álgebra de mapas.

Este trabalho objetivou analisar a suscetibilidade erosiva dos solos do município de Barcarena, no estado do Pará, através da elaboração de cartas de suscetibilidade erosiva. Estas cartas foram geradas a partir do tratamento de mapas temáticos dos atributos, vegetação, pedologia, declividade e uso e ocupação dos solos por meio do seu processamento utilizando software de SIG geográficas, visando gerar subsídios que permitam a utilização desta ferramenta em ambientes similares da região amazônica e que redundarão numa melhor gestão deste recurso.

\section{MATERIAL E MÉTODOS}

O município de Barcarena situa-se a nordeste do estado do Pará entre os paralelos $1^{\circ} 30^{\prime} \mathrm{S}$ a $1^{\circ} 40^{\prime} \mathrm{S}$ e entre os meridianos $48^{\circ} 30^{\prime} \mathrm{W}$ a $48^{\circ} 50^{\prime} \mathrm{W}$ (figura 1). A geologia local faz parte da bacia sedimentar da foz do rio Amazonas; os terrenos são representativos do grupo Pará, caracterizado por depósitos de areia, siltes, argilas e concreções lateríticas (PEREIRA et al., 2010).

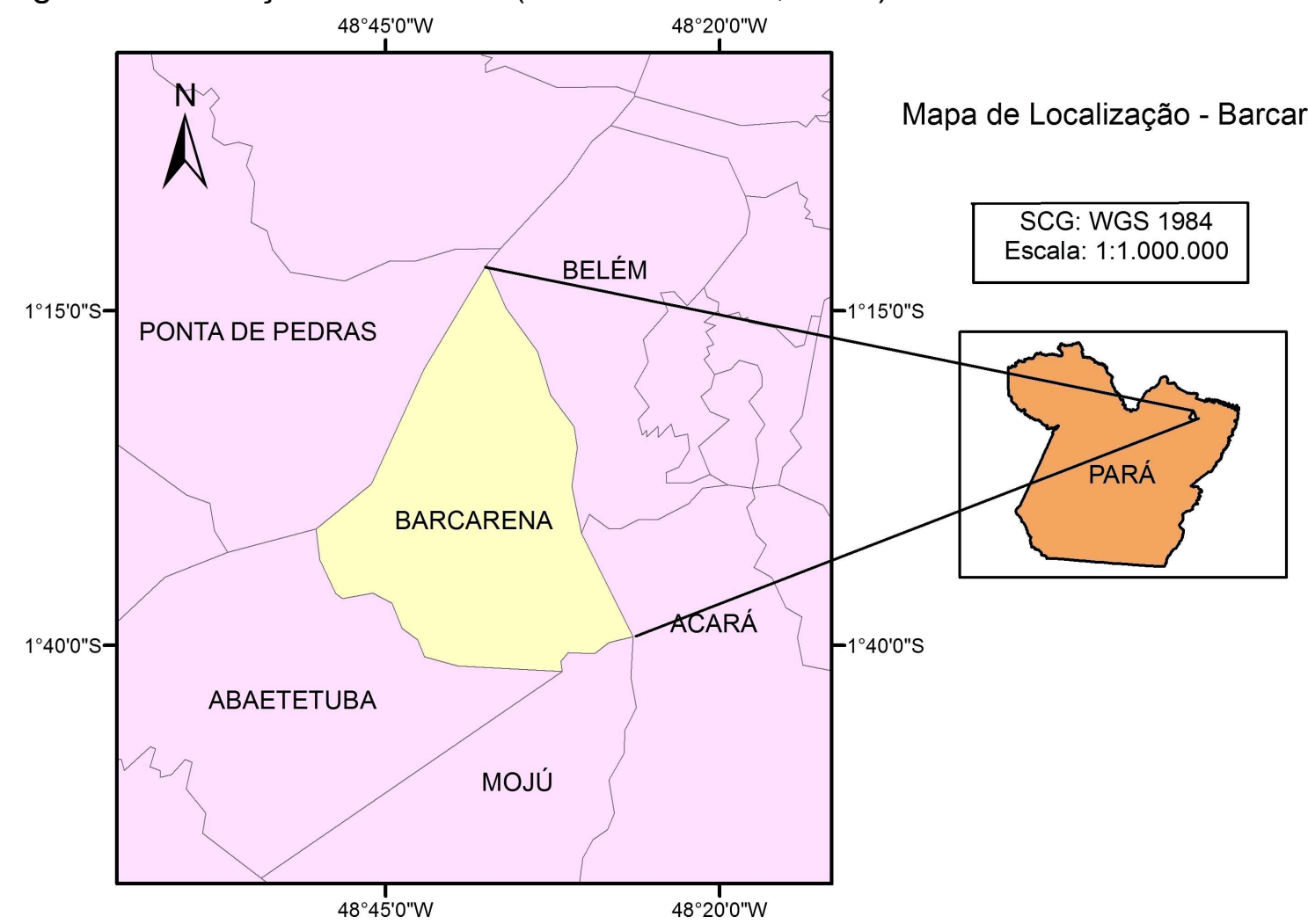

FIGURA 1: Localização de Barcarena - PA

Fonte: Autores, 2015. 
Incialmente foi realizada uma revisão bibliográfica, com o objetivo de identificar os aspectos ambientais para análise da suscetibilidade erosiva do município de Barcarena. Segundo SIMÕES \& OLIVEIRA (2014), os ambientes com características físicas impróprias à ocupação resultantes da combinação de fatores geológicos, geomorfológicos, pedológicos e topográficos, dentre outros, favorecem a ocorrência de processos erosivos e movimentos de massa. Destas características, foram considerados os atributos de vegetação, pedologia (solos), topografia e o uso e ocupação do solo. As informações dos atributos utilizados foram consultadas e obtidas nos formatos shapefile e geotiff nos portais do Instituto Brasileiro de Geografia e Estatística (IBGE), disponível em: mapas.ibge.gov.br / interativos / arquivos / downloads, e no portal da Companhia de Pesquisa de Recursos Minerais (CPRM), disponível em: geobank.cprm.gov.br.

Com as informações obtidas, foi criado um banco de dados com arquivos no formato shapefile e imagens no formato geotiff para posterior aplicação destes no software Quantum Gis (QGis) versão 1.8.0, onde foram utilizadas as ferramentas do Spatial Analysis e Analysis Tools do software.

Para a geração do mapa de declividade foi realizado o geoprocessamento utilizando imagem de relevo do município em estudo. As imagens estão disponibilizadas no portal da CPRM (geobank.cprm.gov.br), no mosaico de imagem SRTM (Shuttle Radar Topography Mission), folha SA-22, no formato raster (geotiff) e com o georreferenciamento efetuado no sistema de coordenadas geográficas DATUM WGS84. Os mapas temáticos dos demais fatores foram gerados com base nos dados em formato shapefile obtidos no portal do IBGE (mapas.ibge.gov.br/interativos/arquivos/downloads).

Para a geração do mapa de pedologia, foi coletado no portal do IBGE os arquivos shp, shx e dbf com informações pedológicas do território brasileiro, com o auxílio do QGis, foi realizado o clip com base no limite do município em estudo e a identificação e rotulação das classes com os tipos de solo. No mapa de vegetação e uso do solo foram realizados os mesmos procedimentos.

Para obtenção do mapa de suscetibilidade erosiva, foi realizada a análise multicritério, que segundo MOURA (2007), é o mapeamento de variáveis por plano de informação e na definição do grau de pertinência de cada plano de informação e de cada um de seus componentes de legenda para a construção do resultado final. A matemática empregada é a simples Média Ponderada, mas há pesquisadores que já utilizam a lógica Fuzzy para atribuir os pesos e notas. Esta análise permitiu a investigação combinada de variáveis, onde foram atribuídas notas para cada atributo ambiental empregado na análise de suscetibilidade erosiva, além desta, foi aplicado também a ferramenta de álgebra de mapas (Map Algebra), esta ferramenta permite a combinação dos produtos considerando o peso de cada variável (uso da terra, pedologia, declividade e vegetação). Essas metodologias foram executadas no software de informação geográfica QGis, versão 1.8.0.

De acordo com BENAVIDES SILVA \& MACHADO (2014); BONNA (2011), foram definidos os pesos de cada aspecto considerado na análise e notas para seus respectivos atributos, considerando suas influências nos processo erosivas, a tabela 1 demonstra como foram distribuídos os pesos e as notas para a geração do mapa síntese. Os pesos variaram de 0-1 e as notas de 0-10. 
TABELA 1: Notas e Pesos para análise multicritério.

\begin{tabular}{|c|c|c|c|}
\hline Solo (peso - 0,20) & Uso da terra (peso - 0,30) & $\begin{array}{l}\text { Vegetação } \\
\text { (peso - 0,15) }\end{array}$ & $\begin{array}{c}\text { Declividade (peso- } \\
0,35)\end{array}$ \\
\hline Massa d'água - 1 & $\begin{array}{l}\text { Entre } 50 \text { e } 25 \% \text { agropecuária } \\
-10\end{array}$ & $\begin{array}{l}\text { Massa d'água - } \\
1\end{array}$ & $782-2$ \\
\hline $\begin{array}{l}\text { Gleissolo alta } \\
\text { atividade }-6\end{array}$ & $\begin{array}{l}\text { Entre } 25 \text { e } 10 \% \text { agropecuária } \\
-9\end{array}$ & $\begin{array}{l}\text { Vegetação } \\
\text { secundária - } 5\end{array}$ & 782 até $8107-5$ \\
\hline $\begin{array}{l}\text { Gleissolo baixa } \\
\text { atividade }-5\end{array}$ & $\begin{array}{l}\text { Menos de } 10 \% \text { agropecuária } \\
-8\end{array}$ & Pioneiras - 3 & 8107 até $33435-9$ \\
\hline \multirow{5}{*}{$\begin{array}{l}\text { Latossolo amarelo - } \\
4\end{array}$} & Usos diversos -7 & & \\
\hline & $\begin{array}{l}\text { Lavouras + Outras } \\
\text { Coberturas }-5\end{array}$ & & \\
\hline & Urbanização - 4 & & \\
\hline & $\begin{array}{l}\text { Lavouras }+ \text { Matas e/ou } \\
\text { Florestas }-2\end{array}$ & & \\
\hline & Lavouras permanentes - 6 & & \\
\hline
\end{tabular}

Fonte: Adaptado de BENAVIDES SILVA \& MACHADO (2014); BONNA (2011).

Com base no banco de dados gerado com as consultas nos portais, foram gerados mapas para cada variável dentro do limite municipal de Barcarena. Os produtos demonstram a distribuição espacial de cada variável e suas diferentes composições conforme figura 2.

No processo de geração do mapa síntese, foram considerados os pesos e notas descritos na tabela 1. As áreas suscetíveis à erosão do município de Barcarena foram divididas em cinco níveis de intensidade erosiva segundo XAVIER et.al (2010), muito baixa, para áreas com níveis entre pouco a não suscetíveis a erosão, baixa, para áreas com níveis pouco suscetíveis, média, para áreas com níveis moderados de erosão, alta, para áreas muito suscetíveis e muito alta, para níveis de extrema suscetibilidade.

\section{RESULTADOS E DISCUSSÕES}

Com a aplicação da metodologia proposta, foram obtidos alguns produtos referentes a cada variável considerada na pesquisa (figura 2), estes foram obtidos com base no banco de dados gerado através de pesquisas nos portais dos institutos de desenvolvimento já citados.

O mapa interativo de declividade mostrou predominância de relevo suavemente ondulado (3-8\%), que segundo BENAVIDES SILVA \& MACHADO (2014), consiste em uma superfície de topografia pouco movimentada, constituída por um conjunto de colinas e/ou outeiros, apresentando declives acentuados, que leva ao movimento de massa, escoamento laminar, sulcos e ravinas.

A pedologia do município em estudo mostrou os tipos de solo da área de Barcarena, Gleissolos Hápilicos de Argila com alta e baixa atividades, Latossolo Amarelo Distrófico, foram as classes identificadas. Segundo FILHO et al., (2014), o relevo predominantemente plano nas classes dos Gleissolos, sugerem baixos riscos de perdas de solos por erosão. No caso dos Latossolos, a permeabilidade acentuada desses solos é resultado da baixa relação textural, que associadas à estrutura bem desenvolvida (tipicamente entre blocos e granular) e teores consideráveis de matéria orgânica, contribuem para a maior resistência à erosão hídrica desses solos. 
O mapa de vegetação demostrou presença de vegetação secundária, vegetação pioneira com influência fluvio-Marinha. SALOMÃO (2012) destacou a importância da cobertura vegetal como "defesa natural de um terreno contra a erosão", sugerindo que a simples presença de cobertura vegetal já ameniza os processos erosivos.

O mapa de uso e ocupação do solo apresentou classes como, lavouras com matas e/ou florestas, lavouras com outros tipos de cobertura, lavouras permanentes, com usos diversos, área com menos de 10\% com uso agropecuário, área com mais de $10 \%$ e menor que $25 \%$ com uso agropecuário, área com mais de $25 \%$ e menor que $50 \%$ com uso agropecuário e área urbanizada. As áreas destinadas a agropecuária podem acelerar bastante os processos erosivos, SILVA (2011) destacou que a passagem do gado em locais preferenciais promove a compactação do solo e criando locais preferenciais para a passagem da água, gerando formas mais avançadas de erosão, como ravinas e pequenas voçorocas, com base no mapa de uso e ocupação do solo na figura 2, as áreas destinadas ao uso agropecuário representam mais de $50 \%$ da área total do município.

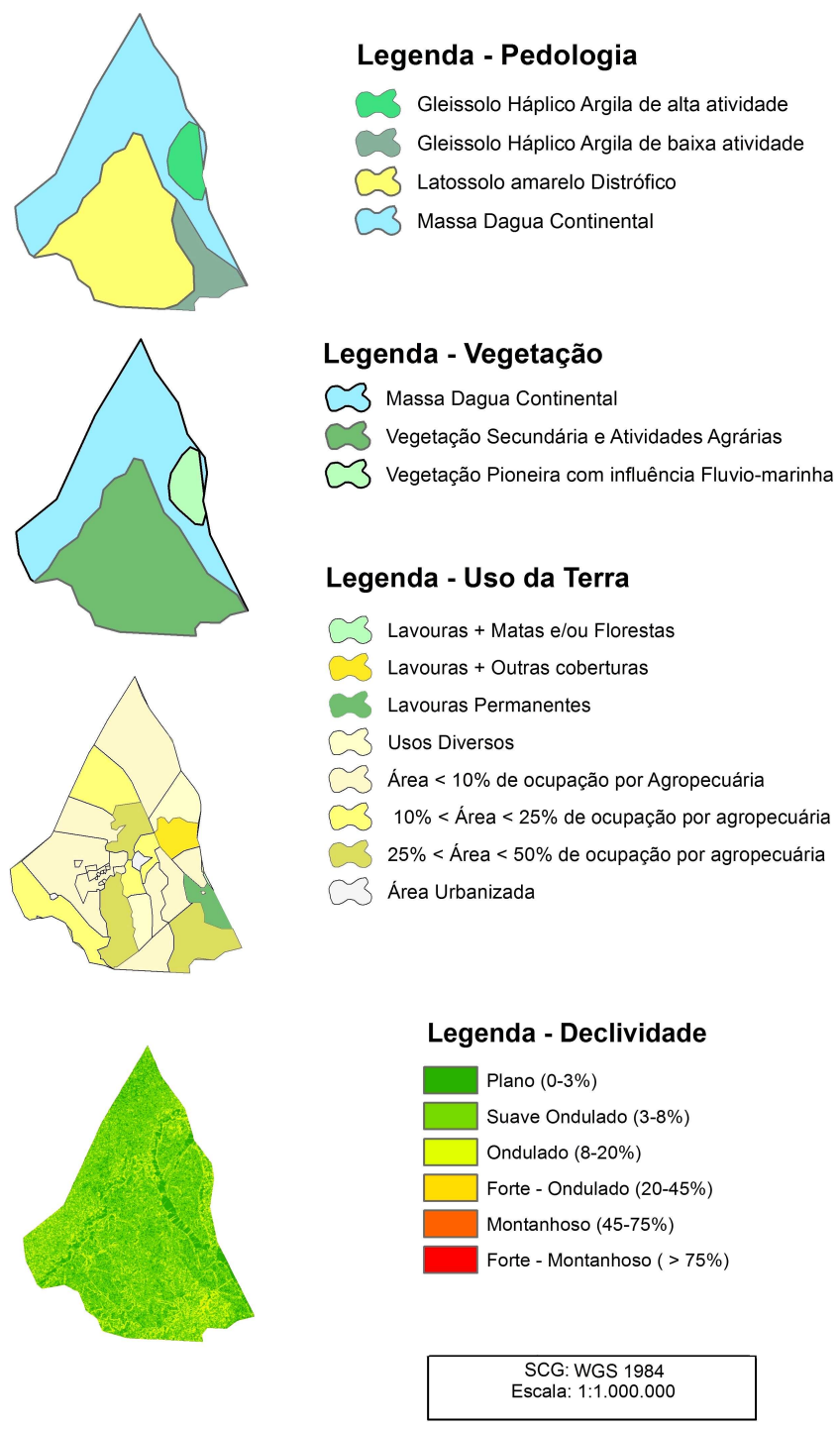

FIGURA 2: Mapas com as variáveis

Fonte: Autores, 2015. 
De acordo com a figura 2 foi possível identificar a distribuição dos atributos na área de estudo. Os mapas de pedologia, vegetação, uso da terra e declividade foram combinados na análise multicritério e posteriormente foi aplicado o método de álgebra de mapa com base nos pesos e notas da tabela 1. Como resultado do método algébrico foi gerado o mapa síntese de suscetibilidade erosiva do município de Barcarena (figura 3).

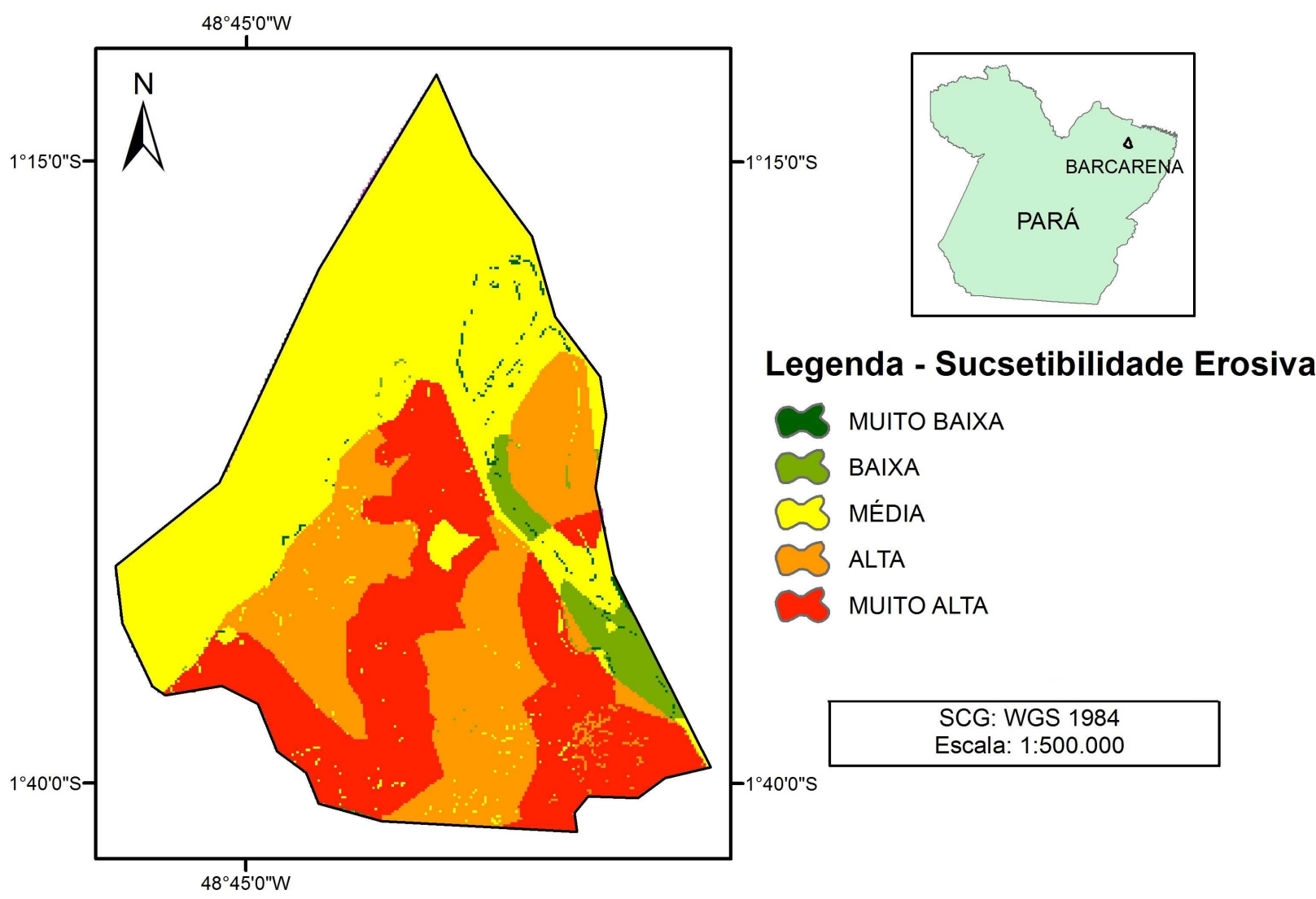

FIGURA 3: Mapa Síntese de suscetibilidade erosiva Fonte: Autores, 2015.

Com base na figura 3, foi possível identificar as áreas do município de Barcarena que estão passíveis a processos erosivos. O município possui uma área correspondente a aproximadamente 1.305,57 $\mathrm{km}^{2}$, desta área $42,12 \%\left(549,88 \mathrm{~km}^{2}\right)$ enquadraram-se, como área suscetibilidade erosiva Média, $28,06 \%\left(366,43 \mathrm{~km}^{2}\right)$ com de suscetibilidade Muito Alta, 25,88\% (337,92 $\left.\mathrm{km}^{2}\right)$ como de Alta, $3,43 \%(44,73$ $\left.\mathrm{km}^{2}\right)$ como de Baixa e apenas $0,51 \%\left(6,61 \mathrm{~km}^{2}\right)$ como de suscetibilidade erosiva Muito Baixa.

A figura 3 indica que a suscetibilidade erosiva Muito Alta está localizada na região centro sul do município onde predominam solos do tipo Latossolo Amarelo Distrófico, com predomínio de Vegetação Secundária, com forte influência atividade Agropecuária. A susceptibilidade degradativa dos solos do município está fortemente influenciada pelas atividades antrópicas, com uso e ocupação do solo dominado 
pela atividade agropecuária, considerado como um dos principais fatores da degradação do solo por SIMÕES \& OLIVEIRA (2014).

A presença de Vegetação Secundária nas áreas identificadas com susceptibilidade Muito Alta, pode não ter contribuído com a amenização da suscetibilidade devido o peso atribuído a este fator (10\%), certamente a influência antrópica (uso do solo) com peso de $30 \%$ foi a principal causa da degradação dos solos, principalmente devido a supressão da vegetação, reforçando a constatação de ALMEIDA et al., (2008) que verificou que a maior susceptibilidade à erosão do solos ocorre em áreas que não apresentam mais sua vegetação nativa.

As áreas de Média suscetibilidade erosiva, com expressivo 42,2\% da área do município, provavelmente foram influenciadas pela topografia do município, fator considerado na pesquisa como mais atuante com peso de $35 \%$ e pelo fator pedologia (20\%). A topografia dominante é suavemente - ondulado, destacando um relevo pouco acidentado e pouco suscetível à movimentação de massas. Os solos são da classe Latossolo, onde a mineralogia característica de ambientes oxidantes deste tipo de solos favorece boa estruturação, sendo um dos motivos da sua baixa erodibilidade, identificado por SILVA et al. (2009) e dos Gleissolos, que apresentam suscetibilidade à erosão laminar muito forte (NETO \& ALEIXO, 2014).

\section{CONCLUSÃO}

Os estudos que buscam a qualificação ou quantificação da fragilidade ambiental de uma determinada área são de extrema relevância para o planejamento e gestão territorial da mesma. Nesse caso, a análise de suscetibilidade erosiva pode ser considerada uma ferramenta apropriada para realização de um diagnóstico ambiental, pois através desta pode-se obter informações sobre o ambiente em questão, identificando as melhores metodologias de remediação ou recuperação.

Neste estudo, a análise multicritério mostrou-se eficiente, pois através desta foi possível realizar a combinação de todas as variáveis empregadas no estudo. $O$ método de álgebra de mapas, também mostrou-se uma metodologia útil, já que através do emprego desta ferramenta foi possível a geração do mapa síntese de suscetibilidade erosiva.

Através dos resultados obtidos com a pesquisa foi possível observar que o município de Barcarena apresenta uma fragilidade ambiental considerável, onde a maior parte de sua área está passiva a processos erosivos de Média intensidade, logo é importante que os gestores e a população, tenham consciência do cenário ambiental em que o município de Barcarena se enquadra.

Deste modo, estudos com objetivos e metodologias semelhantes com o desta pesquisa devem ser aplicados, modelados e financiados, pois são de extrema importância para o gerenciamento ambiental de áreas que estão cada vez mais expostas as atividades antrópicas.

\section{REFERÊNCIAS}

ALMEIDA, W. S; SOUSA, N. M; CARVALHO, J. C. Produção de mapas de zonas homólogas de relevo e de uso do solo, a partir de dados de modelos numéricos de terreno e de imagem Quick Bird, como passos intermediários em um diagnóstico da susceptibilidade à erosão, no entorno da usina hidrelétrica Corumbá IV (GO). Anais XIV Simpósio Brasileiro de Sensoriamento Remoto, Natal, Brasil, p. 5563-5570, 2009. 
BENAVIDES SILVA, V. C; MACHADO, P. S. SIG na Análise Ambiental: Susceptibilidade Erosiva da Bacia Hidrográfica do Córrego Mutuca, Nova Lima Minas Gerais. Revista de Geografia (UFPE) V. 31, n.2, 2014.

BONNA, J. L. Mapeamento Pedológico e de Suscetibilidade Erosiva no Alto Córrego Prata (Ouro Preto-MG). Instituto de Geociências, Universidade Federal de Minas Gerais, 2011.

CPRM - Companhia de Pesquisa de Recursos Minerais. Dados \& Produtos - Mapa de Declividade em Percentual do Relevo Brasileiro, disponível em: geobank.cprm.gov.br, 2010.

COSTA, R. A; JÚNIOR, C. C. S; NISHIYAMA, L. Susceptibilidade aos Processos Erosivos do Meio Físico em Morrinhos - GO. GEONORDESTE, Ano XXI, n.2, 2010.

FILHO, B. C; BERING, S. B; CALDERANO, S. B; GUERRA, A. J. T. Suscetibilidade dos Solos à Erosão na Microbacia do Córrego Fonseca, Região Serrana do Estado do Rio de Janeiro. Anais do Simpósio Regional de Geoprocessamento e Sensoriamento Remoto, Aracaju, Brasil, 2014.

IBGE - Instituto Brasileiro De Geografia e Estatística. Geociências - Produtos, disponível em: mapas.ibge.gov.br/interativos/arquivos/downloads, 2010.

MAGRI, R. A. F. Análise da Suscetibilidade à erosão da região do Médio Rio Grande (MG). Escola de Engenharia de São Carlos, Universidade de São Paulo, 2013.

MOURA, A. C. M. Reflexões Metodológicas como Subsídio para Estudos Ambientais Baseados em Análise de Multicritérios. Anais do XIII Simpósio Brasileiro de Sensoriamento Remoto, Florianópolis, Brasil, p.2899-2906, 2007.

MINELLA, J. P. G.; MERTEN, G. H.; REICHERT, J. M.; SANTOS, D. R. Identificação e implicações para a conservação do solo das fontes de sedimentos em bacias hidrográficas. Revista Brasileira de Ciência do Solo, v.31, p.1637-1646, 2007.

NETO, J. C. A. S; ALEIXO, N. C. R. Apropriação da Natureza e Processos Erosivos na Região do Médio Solimões - AM. Revista GeoUECE, v. 3, no 4, p. 151-176, jan./jun. 2014.

PEREIRA, S. F. P; SANTOS, L. R; SILVA E SILVA, C; MIRANDA, R. G; GOMES, T. L. D. Uso da Análise Multivariada na Avaliação dos níveis de Cádmio, Crômio, Ferro, Zinco, Cobre, Chumbo e Alumínio e suas intercorrelaçõesno compartimento Hídrico da Região de Barcarena-Pa. Safety, Health and Environment World Congress. São Paulo, BRAZIL, 2010.

LOLLO, J. A; SENA, J. N. Estabelecimento de Suscetibilidade a erosão - diferentes técnicas para diferentes etapas de tomada de decisão. VII Congreso de Meio Ambiente /AUGM, UNLP, La Plata Argentina, 2012. 
SALOMÃO, F. X. T. Controle e Prevenção dos Processos Erosivos. In: GUERRA, Antônio José Teixeira; SILVA, Antônio Soares da; BOTELHO, Rosangela Garrido Machado (Org.). Erosão e Conservação de Solos - Conceitos, Temas e Aplicações. Bertrand Brasil. Rio de Janeiro, p. 229-267, 2012.

SILVA, A. M.; SILVA, M. L. N.; CURI, N.; AVANZI, J. C.; FERREIRA, M. M. Erosividade da chuva e erodibilidade de Cambissolo e Latossolo na região de Lavras, sul de Minas Gerais. Revista Brasileira de Ciência do Solo, v.33, p.18111820, 2009.

SILVA, A. S. Mineração e Áreas de Preservação Permanentes (Apps) em Santo Antônio de Pádua - RJ. Revista Sociedade \& Natureza, Uberlândia, ano 23 n. 2, 173-185, 2011.

SIMÕES, P. M. L; OLIVEIRA, C. V. Avaliação da Susceptibilidade à Erosão e aos Movimentos de Massa no município de Ibirité. Geonomos, Revista do Centro de Pesquisa Professor Manoel Teixeira da Costa, Instituto de Geociências, Universidade Federal de Minas Gerais, 2014.

SOUSA, H. C; SANTOS, W. A. A. Atuação, Monitoramento e Análise de Processos Erosivos no âmbito de Parques Eólicos: Estudo de caso nas Regiões Litorânea e Agreste do Nordeste Brasileiro. Brazil Windpower, Conference and Exhibition, Rio de Janeiro, Brasil, 2014.

XAVIER, V. F; CUNHA, K. L; SILVEIRA, A; SALOMÃO, F. X. E. Análise da Suscetibilidade à Erosão Laminar na Bacia do Rio Manso, Chapada dos Guimarães, MT, Utilizando Sistemas De Informações Geográficas. Revista Brasileira de Geomorfologia, v.11, n.2, p.51-60, 2010. 